\title{
MANAGING COMMODITY PROCUREMENT RISK THROUGH HEDGING
}

\author{
Paul Kleindorfer \\ Enver Yücesan \\ Technology and Operations Management Area \\ INSEAD \\ 77305 Fontainebleau, FRANCE
}

\begin{abstract}
The key to corporate value is in making good investments and in harvesting the cash flows from these investments through effective execution. The latter is improved through stability of plans. Cash flows, however, can be disrupted by movements in external factors such as exchange rates, commodity prices, potentially compromising the stability of plans and, in the worst case, undermining the company's ability to invest in otherwise good opportunities. Risk management is therefore directed at providing increased stability of plans, increased fidelity to strategic budgets, and, in the process, at understanding better the supply markets. The particular focus in this paper is on financial hedging tools designed to limit procurement exposure (i.e., control the maximum hedge-adjusted spend) within the context of highly volatile commodity markets.
\end{abstract}

\section{INTRODUCTION}

Over the past few years, prices of commodities such as energy, cocoa, sugar and milk powder, as well as those closely linked to crude oil, such as plastics, have risen significantly. Moreover, these increases have been accompanied by wild fluctuations in the world markets, as depicted in Figure 1. These price movements have prompted procurement professionals to explore a wide portfolio of supply risk management (SRM) strategies, including some financial hedging techniques to limit their exposure. There are four main drivers or causal factors affecting the costs and benefits of SRM for a particular commodity in a firm with major commodity risk exposure:

- Characteristics of the Commodity: These include attributes such as total spend, anticipated scarcity and volatility of prices of the commodity, interdependence of the commodity with other markets (e.g., crude) which could be undergoing significant transformations, expected and actual regulatory influences that might introduce political risk factors beyond market factors, grades and other constraints.

- Characteristics of the Supply Chain for the Commodity: Factors affecting the nature and payoff from SMR include the integrity of the supply chain, criticality of the commodity in terms of the consequences of disruption of normal supplies, regional vs. global control of the supply chain and sourcing arrangements.

- Characteristics of Markets for the Commodity and Other Related Commodities: These characteristics relate to such matters as competitiveness (liquidity, global reach, etc.) of the market, transparency of financial instruments related to it, data sources available, brokerage and other competent services available. 
- Company Competencies for the Commodity: These relate to how well equipped the focal company is currently to understand and manage the supply-related uncertainties and risks for the commodity itself, as well as for other related commodities. Needless to say, a company without the necessary expertise would run the risk of wasting resources or worse, if maximum exposure from hedging activities is not properly controlled.

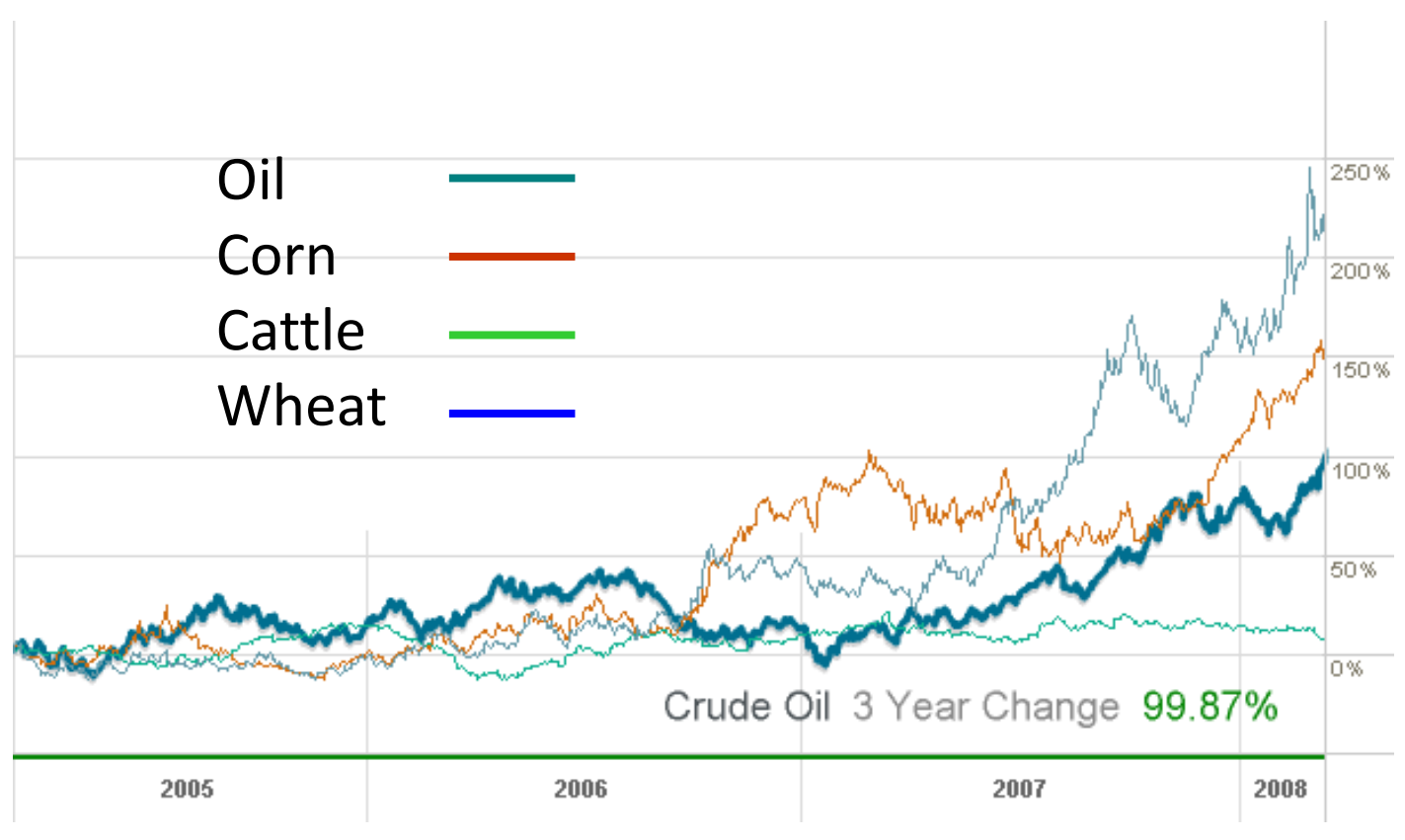

Figure 1: Volatility in commodity markets.

\subsection{Illustrative Example: Plastics}

Plastics for containers come in many sizes and grades, but the underlying chemical components remain the same, with the basic chemicals (referred to as "resins") being high-density polyethylene (HDPE), polypropylene (PP) and polyethylene terephthalate (PET). A fast-moving consumer goods (FMCG) company such as Unilever is a major consumer of plastic bottles and lids to package its products, spending around 400 million euros on plastics in 2006.

In spite of a complex supply chain, depicted in Figure 2, plastics are highly commoditized. As a key commodity, the global over-the-counter plastics trade is quite transparent with well-developed parallel financial markets since the price of both PP and HDPE is highly correlated with the price of their raw materials, crude oil and natural gas. This suggests that hedging instruments for plastics spend could be either directly in HDPE, PP or PET, or through positions in the underlying raw materials of crude oil and natural gas.

Price volatility peaked at $25 \%$ in 2006 . The key concern for this category is thus to achieve price stability. Unfortunately, market forecasts are typically far from accurate, which, in turn, triggers an interest in pursuing parallel risk management opportunities, both as a possible source of risk hedging as well as of improving the quality of the information underlying the sourcing and contracting decisions for plastics.

Figure 3 shows the structure and complexity of the plastics hedging problem. For a specific region, the problem begins with aggregate end product demand for different bottles and containers, as determined 
by market forecasts. These, in turn, imply ex-ante demand for different resins (HDPE, PP, PET) in the periods $t=1, \ldots, T$ (think of these as quarters). The basic question in terms of hedging strategies is whether to take positions (i.e., buy swaps and other derivative instruments from brokers or directly on the London LIFFE or other exchanges) in crude oil (an indirect hedge) or in the resins themselves.

\section{PP and HDPE Chains Overlap}

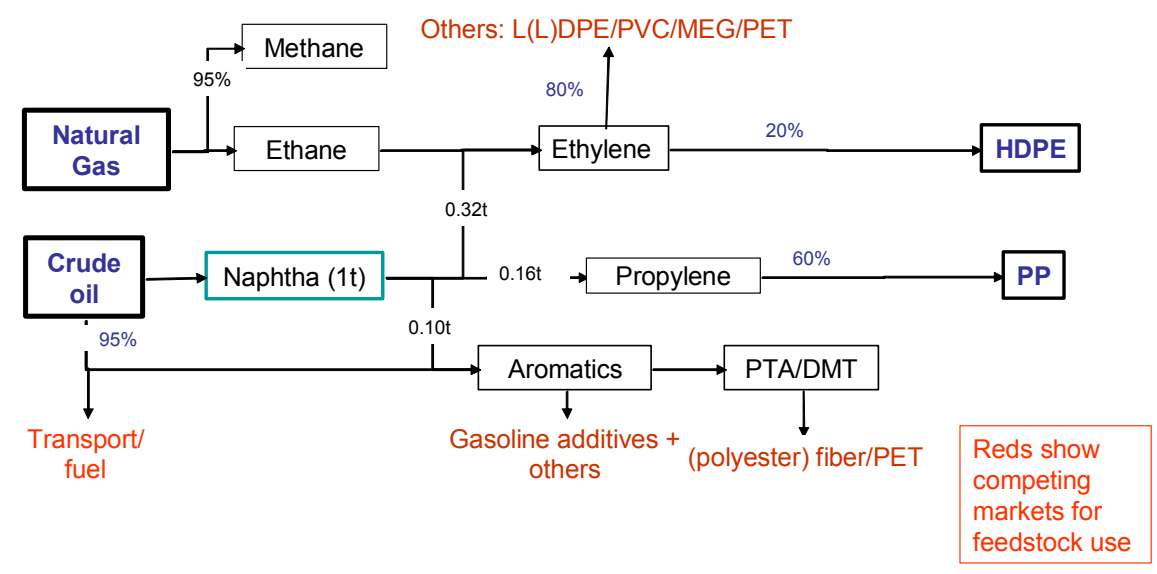

Various markets outside the resin market affect resin prices. Crude oil (energy and transportation) is the most prominent affecting both PP and HDPE.

Figure 2: Overlapping HDPE, PP, and PET supply chains.

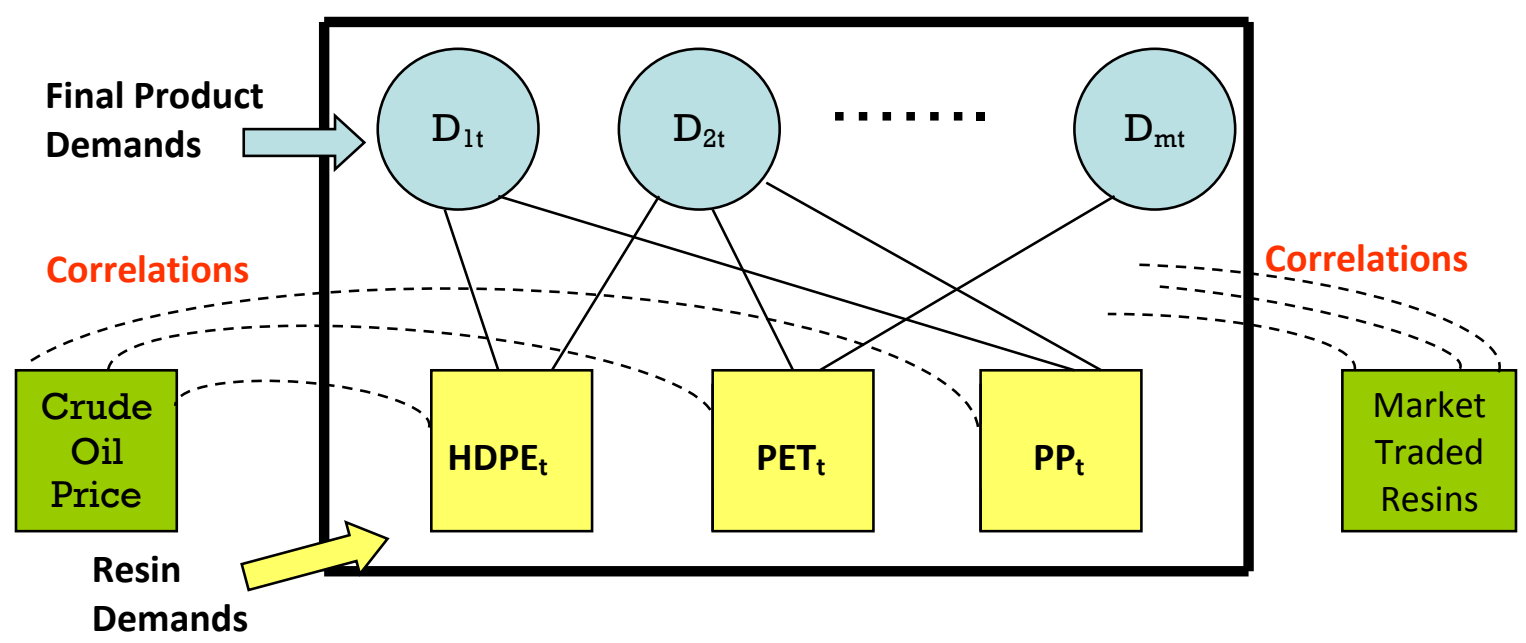

Figure 3: Demand for plastic bottles. 
As an example, Table 1 summarizes demand and mean prices for three demand regions (NE, SE and West) in the North American market for HDPE for the four quarters of 2006 (as forecast at the beginning of 2006). The standard deviation of HDPE demand in each quarter was expected to be about $10 \%$ and the standard deviation of the price was expected to be about $25 \%$ of mean price, with strong correlation of prices across regional suppliers. During 2006, based on futures contracts trading on $1 / 1 / 06$, the average price for Brent crude oil was expected to be $\$ 65.32$ per barrel (with a standard quarterly deviation of \$6.17). For the same period, based on historical data, the correlation between crude oil prices and that of resins was around 0.65 .

Table 1: Demand volumes (metric tons) and prices (\$/ton) over 4 quarters in 2006.

\begin{tabular}{|l|c|c|c|c|}
\hline & Quarter 1 & Quarter 2 & Quarter 3 & Quarter 4 \\
\hline Demand - NE & 15557 & 16159 & 14532 & 16858 \\
\hline Demand - SE & 16550 & 16734 & 14985 & 15485 \\
\hline Demand - W & 19150 & 17810 & 18283 & 18895 \\
\hline Price - NE & 1211 & 1304 & 1405 & 1626 \\
\hline Price - SE & 1309 & 1341 & 1521 & 1517 \\
\hline Price - W & 1119 & 1260 & 1387 & 1578 \\
\hline
\end{tabular}

Given this setting, commodity procurement should address the following challenges:

- Should a procurement organization engage in risk hedging activity for its plastics resins, possibly including taking positions in crude oil?

- Is this financial approach to hedging cash flows the right approach?

- Should Procurement be the one to implement this approach or should it be done by Treasury?

- What controls should be put in place to make sure that hedging is limited to the specific purpose of improving performance, and not for speculative purposes?

- What benefits, if any, would information provided by this hedging strategy bring to improving buying performance and contracting with respect to plastics purchases?

The remainder of the paper is organized as follows. In the next section, we briefly introduce the supply portfolio problem. Section 3 discusses modeling to support decision making. Section 4 reports the key insights from the analysis while Section 5 highlights the implementation challenges. Concluding comments are presented in section 6.

\section{THE SUPPLY PORTFOLIO PROBLEM}

The central question to be addressed in supply portfolio management is concerned with the mix of supply contracts, options contracts, and swaps to provide assured physical supply of needed inputs for production, together with appropriate financial hedges for the associated cash expenditures for these inputs. Physical supplies can come either from pre-qualified sellers or directly from various spot markets. In supply management for commodities, different grades and specifications for commodities often require prior contracting and procurement relations with pre-qualified suppliers. These alternative situations give rise to various forms of commodity risk management, as shown in Table 2 below. The standard problem of commodity sourcing and hedging, the Supply Portfolio Problem (SPP), however, can be stated as follows:

Maximize Expected Profits (where the decision choices are the amounts to contract for from each available physical and financial contract) 


\section{Subject to:}

- Physical delivery constraints (to assure delivery of needed inputs)

- Financial risk constraints (on maximum exposures or on allowable losses from financial instruments used for hedging)

- Constraints defining the instruments themselves (puts, calls, swaps, contract parameters such as minimum take provisions and flexibility bands, etc.)

This optimization problem is not solved once and for all, but on a continuing basis as uncertainties regarding demand, spot prices, and contract prices are resolved. To the extent that contracts allow flexibility in execution, these are executed to optimize profits on the day by executing all options that are "in the money" or needed for physical fulfillment. This problem "on the day" can sometimes be interesting, but in theory, it is straightforward and solved by some computer-based algorithm that picks the best options on the day to execute for both physical coverage and financial return. The more interesting problem, which requires both judgment and computer support, is the medium to long-term, on-going SPP. Various forms of the SPP have been developed for various types of markets, whose details differ considerably across these markets. Except in very simple cases, the solution to the SPP must be accomplished using Monte Carlo simulation together with a simulation optimization engine (Hong and Nelson 2009).

Table 2: Alternative contexts for commodity risk management of supply.

\begin{tabular}{|l|l|l|}
\hline \multicolumn{1}{|c|}{ Description of Context } & $\begin{array}{l}\text { Instruments used in Optimal } \\
\text { Portfolio }\end{array}$ & \multicolumn{1}{|c|}{ Examples } \\
\hline $\begin{array}{l}\text { Cost and access differences } \\
\text { are small and only standard } \\
\text { commodities are sourced }\end{array}$ & $\begin{array}{l}\text { Bilateral contracting and fi- } \\
\text { nancial hedge instruments are } \\
\text { defined on a common market } \\
\text { and optimized jointly }\end{array}$ & $\begin{array}{l}\text { Energy } \\
\text { Commodity metals }\end{array}$ \\
\hline $\begin{array}{l}\text { Cost and access differences } \\
\text { are large and only standard } \\
\text { commodities are sourced }\end{array}$ & $\begin{array}{l}\text { Bilateral contracting is used } \\
\text { for most physical procure- } \\
\text { ment, with spot market used } \\
\text { for topping up supply, and for } \\
\text { financial hedge instruments }\end{array}$ & $\begin{array}{l}\text { Logistics services (standard air } \\
\text { and maritime cargo) }\end{array}$ \\
\hline $\begin{array}{l}\text { Non-standle (beef), hogs and } \\
\text { lare sourced, but their prices } \\
\text { are highly correlated with } \\
\text { those of standard commodi- } \\
\text { ties }\end{array}$ & $\begin{array}{l}\text { Bilateral contracting is used } \\
\text { for all physical procurement, } \\
\text { with financial hedge instru- } \\
\text { ments, defined on correlated } \\
\text { standard products, used as an } \\
\text { overlay for hedging }\end{array}$ & $\begin{array}{l}\text { Plastic resins and commodity } \\
\text { chemicals }\end{array}$ \\
\hline
\end{tabular}

\section{MODELING}

Before exploring the details of the simulation, the decision-making process, as reflected in Figure 4, should be emphasized. This first step is important in identifying the role of the simulation model in supporting decisions: the model is developed using relevant data, but also with subjective judgment anchored in the business context as well as company regulations and constraints. The validated model is then used 
in the estimation of key performance metrics that can be deployed not only in assessing the buying performance and the effectiveness of risk management policies, but also fed back into the decision process to refine the data and the understanding of the overall context. It is important early in the discussion to highlight the benefits and, even more importantly, the costs of hedging, which include:

- Cost of establishing and maintaining a capability to engage in hedging, including establishing relationships with brokers, markets, etc., and the acquisition of needed data. It should be noted that these costs are complementary to the costs of effective supply management and can bear important fruit in improving supply management.

- Expected cost of hedge instruments (brokers and financial intermediaries will extract a fee for taking the other side of calls or swaps. These expected costs are easily calculated by simulation and are analogous to insurance premiums for car or homeowners insurance.

- Worst-case costs (or maximum exposures) from hedge instruments that reflect that maximum ex post payments by a company undertaking hedging. If the company only assumes long call positions (i.e., buys call options), then the maximum exposure is the number of such options times the option price. If the options are not "in the money", this would be the maximum ex post exposure. If the company buy swaps or takes short positions on calls or puts, then much larger exposures can result if the market goes the wrong way. Typically, a company would have very strict control limits on worst-case exposures from hedging.

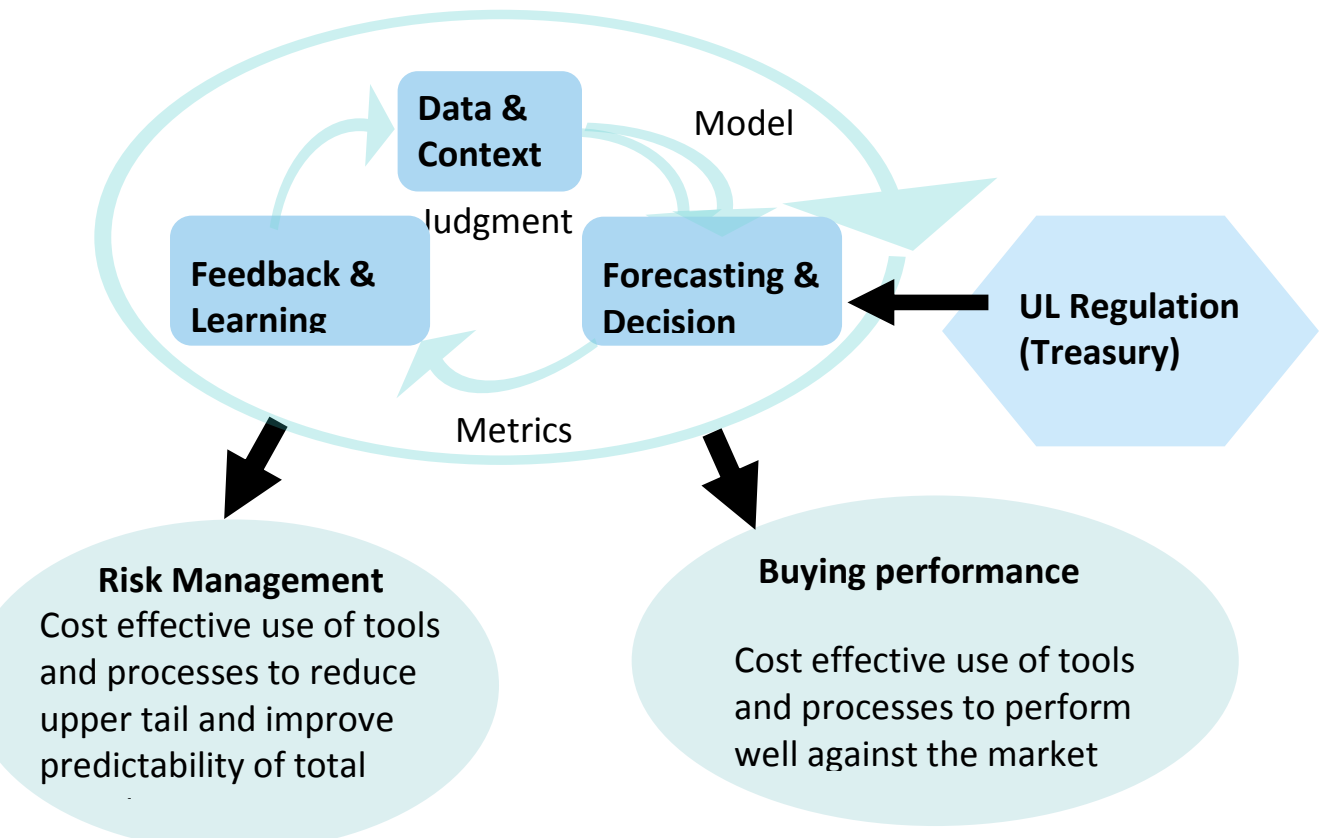

Figure 4: The decision-making context.

Once the rules are clearly established, modeling can proceed as follows (Crouhy, Mark, and Galai 2000):

1. Start with product and market structure and determine the pattern of procurement and correlated markets that could provide risk management hedges.

2. Analyze historical data to obtain relevant random variables (demand, price, and correlations).

3. For a given pattern of procurement choices, which give rise to the unhedged probability distribution of Spend, analyze risk management overlays that could (at a cost) reduce right tail spend-atrisk (SaR) exposure. 
4. Determine the efficient frontier that trades off "increased total Spend" against "decreased right hand tail exposure."

While there exists a rich portfolio of hedging instruments, we consider only two such tools in this paper for illustrative purposes: call options and swaps. A call option gives the holder the right, but not the obligation, to buy the spot asset on or a before a predetermined date (the maturity date) at a certain price (the strike price), which is agreed today. Inversely, a put option gives the holder the right, but not the obligation, to sell the spot asset on or before the maturity (aka., expiration, exercise, strike) date at the strike price.

Similarly, a swap is an agreement whereby a floating (or market or spot) price is exchanged for a fixed price over a specified period. A swap buyer pays the fixed leg and receives the floating leg. A swap seller pays the floating leg and receives the fixed leg. Swaps are financial agreements, but they essentially ensure that (for the contracted volume of the swap) the swap buyer will pay the exact price of the swap for the commodity in question.

\section{ANALYSIS}

A simulation model in Crystal Ball ${ }^{\mathbb{B}}$ was constructed to evaluate various risk hedging strategies for the HDPE spend. Alternative portfolios were evaluated in terms of the total expected spend on HDPE, including the cost of any hedge instruments used. Also of interest were "exceedance probabilities" for various upper limits (or targets) on total annual spend for HDPE-NA. Below are the results for the fourth quarter of 2006, based on the mean values of price and demand quantities at the beginning of 2006. Table 3 shows the assumptions underlying the simulation (all distributions were tested and found to be well approximated by the log-normal distribution). Table 4 shows the results of using 50,000 Call Options in HDPE CMAI NA Spot Underlying and Table 5 shows the results of using HDPE call options plus Brent crude oil swaps (50,000 Call Options in HDPE CMAI NA Spot Underlying and 50,000 Crude Oil Swaps on NYFE). In each case, the expected value of both the hedged and unhedged Spend are shown. The unhedged value is simply in the cash outlay for HDPE in the market. The "Hedged Spend" is this cash outlay for procurement adjusted by the cash flows (positive or negative) resulting from the hedge instruments purchased. A number of other combinations of calls and swaps could also be considered, but these two examples illustrate the general consequences of hedging.

Table 3: Assumptions on $4^{\text {th }}$ quarter HDPE spend calculation.

\begin{tabular}{|l|c|c|}
\hline & Mean & Std Dev \\
\hline UL Demand for NA HDPE Qtr 4 & $55,000.00$ & $4,400.00$ \\
\hline Crude Oil Price/Barrel Oct 1 & $\$ 68.00$ & $\$ 6.00$ \\
\hline HDPE Price (\$/ton) Oct 1 & $\$ 1,594.00$ & $\$ 106.00$ \\
\hline Correlation of Crude with HDPE & 0.65 & \\
\hline HDPE Option Price/Ton Oct 1 Calls & $\$ 28.25$ & \\
\hline HDPE Execution Price/Ton Oct 1 Calls & $\$ 1,650.00$ & \\
\hline Crude Oil Futures/Swaps (\$/Barrel) & $\$ 72.50$ & \\
\hline
\end{tabular}


Table 4. UL HDPE NA $4^{\text {th }}$ quarter 2006 spend (as predicted on $1 / 1 / 2006$ ).

\begin{tabular}{|l|c|c|}
\hline & Mean & Std Dev \\
\hline Unhedged Quarterly Spend (\$ Million) & 87.74 & 9.23 \\
\hline Hedged Quarterly Spend (\$ Million) & 88.10 & 8.24 \\
\hline Value of Crude Oil Swaps (\$ Million) & 0.00 & 0.00 \\
\hline Value of HDPE Call Options (\$ Million) & -0.36 & 2.25 \\
\hline Prob\{Unhedged Spend > \$100 Million\} & 0.093 & \\
\hline Prob\{Hedged Spend > \$100 Million\} & 0.076 & \\
\hline Prob\{Unhedged Spend > \$110 Million\} & 0.013 & \\
\hline Prob\{Hedged Spend > \$110 Million\} & 0.006 & \\
\hline
\end{tabular}

Table 5. UL HDPE NA $4^{\text {th }}$ quarter 2006 spend (as predicted on $1 / 1 / 2006$ ).

\begin{tabular}{|l|c|c|}
\hline & Mean & Std Dev \\
\hline Unhedged Quarterly Spend (\$ Million) & 87.74 & 9.23 \\
\hline Hedged Quarterly Spend (\$ Million) & 88.32 & 8.25 \\
\hline Value of Crude Oil Swaps (\$ Million) & -0.22 & 0.30 \\
\hline Value of HDPE Call Options (\$ Million) & -0.36 & 2.25 \\
\hline Prob\{Unhedged Spend > \$100 Million\} & 0.093 & \\
\hline Prob\{Hedged Spend > \$100 Million\} & 0.078 & \\
\hline Prob\{Unhedged Spend > \$110 Million\} & 0.013 & \\
\hline Prob\{Hedged Spend > \$110 Million\} & 0.006 & \\
\hline
\end{tabular}

\subsection{Efficient Frontier Analysis}

Just as for standard portfolio theory, one can compute the efficient frontier (EF) for the HDPE problem by using the OptQuest (path search) function of Crystal Ball, proceeding as follows:

- Define the risk appetite parameter $K$ at some value, say, between 0 and 5,000,000. One can choose an upper bound on $K$ by observing the effect $K$ has on the Prob $\{$ Hedged Spend $>\$ 100$ Million\}. For $K$ sufficiently large, one is able to check that the value of Prob $\{$ Spend $>\$ 100$ Million $\}=0$ as the optimal solution to the efficient frontier problem does not decrease further; so there is no need to set $K$ any higher.

- For any given $K$ value, we run OptQuest to determine the optimal values of call options on HDPE and crude oil swaps. We minimized the expected value of the "EF metric" (efficient frontier metric), defined as:

Hedged Quarterly Spend $+K^{*}$ Prob $\{$ Hedged Qtrly Spend $>\$ 100$ Million $\}$. 


\section{Kleindorfer and Yücesan}

Note that minimizing this EF metric for different values of $K$ will be the same as finding the lowest expected Hedged Quarterly Spend for a given probability that Hedged Quarterly Spend exceeds \$100 Million.

Varying $K$ from 0 to 40,000,000 (say in intervals of 10,000,000), we plot the values of Expected Hedged Quarterly Spend against the Prob \{Hedged Quarterly Spend exceeds \$100 Million\} in Figure 5, which depicts the efficient frontier. The figure provides answers to the following questions: For any given value of Prob \{Hedged Quarterly Spend $>\$ 100$ Million\}, what is the expected value of Hedged Quarterly Spend? For any given value of Prob $\{$ Hedged Quarterly Spend $>\$ 100$ Million $\}$, what is the expected cost of hedging to achieve this value? The expected cost of hedging would be the difference between the expected value of Hedged Quarterly Spend and Unhedged Quarterly Spend of the portfolio on the efficient frontier for the value of exceedance probability chosen. Also of interest would be the maximum exposure from hedging position necessary to achieve a given Prob $\{$ Hedged Quarterly Spend $>\$ 100$ Million\}.

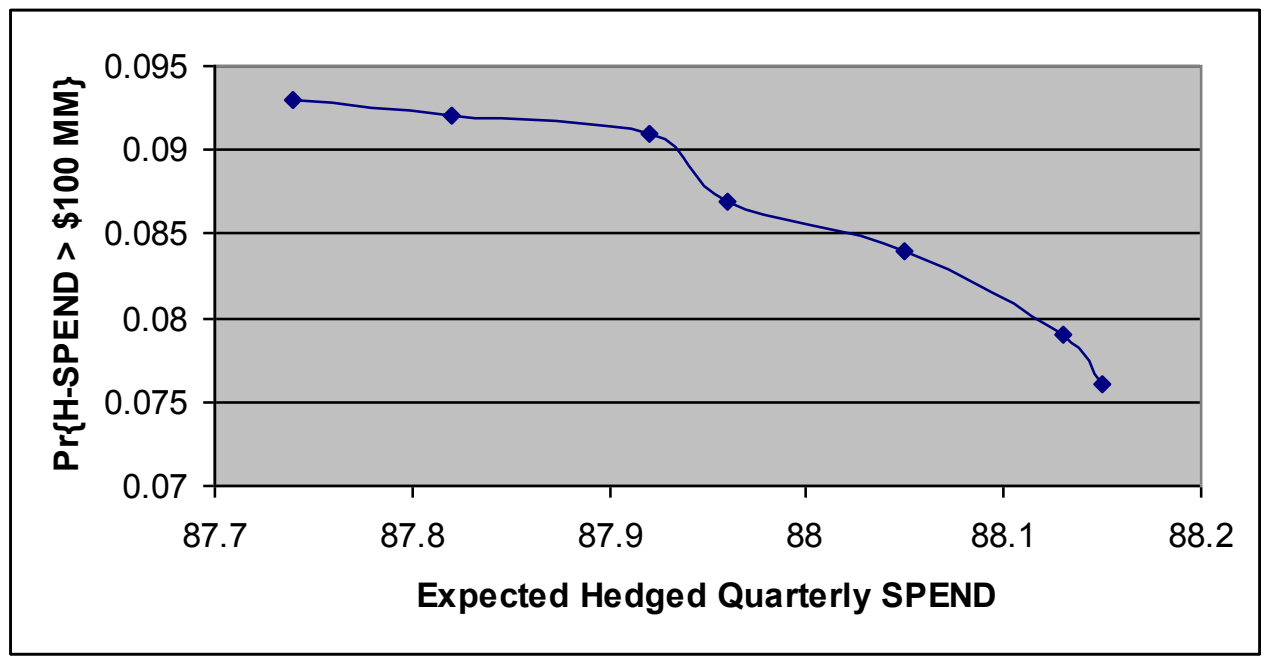

Figure 5: Efficient frontier: Mean hedged quarterly spend versus the probability of exceeding \$100 million in quarterly spend.

\subsection{Key Lessons}

- Hedging costs money: The expected value of Spend will be greater than if one did not buy hedging instruments because (on average) no financial broker or investor will take the other side of these market instruments without some expectation of profit. Note, for example, in Table 4, that the expected cost of the HDPE call options is $\$ 360,000$. The large standard deviation of the value of these call options also tells us that they are "in the money" some of the time (and given their structure, we know that this occurs when the price of HDPE is high and therefore these options help to offset high HDPE prices).

- Hedging cuts off the right hand tail of the spend distribution: Both the standard deviation and the probability that (Spend + Hedging Costs) exceeds a given target threshold will decrease as hedge instruments are purchased. This is, of course, the primary purpose of hedging. Note, for example, in Table 4, that the HDPE call options reduce the probability of exceeding the target spend figure of $\$ 100$ million from 0.093 to 0.076 . They also reduce the probability of exceeding the target spend figure of $\$ 110$ million from .013 to .006 . There are further reductions in the furthest extremes of the spend distribution since it is precisely for these values that the HDPE call options are clearly "in the money". 
- The effectiveness of swaps depends on their correlation with the underlying spend: For example, the assumption of 0.65 correlation between crude oil and NA HDPE prices means that crude oil swaps are not that good a hedge for HDPE price volatility in the present case. Indeed it is clear that the crude oil swap hedge here is actually less effective than the HDPE call options alone in reducing the right hand tail of the HDPE Spend distribution (compare 0.76 vs. 0.78 in Tables 3 and 4, respectively, in reducing the exceedance probability for a Target of $\$ 100 \mathrm{MM}$ ), primarily because these swap options are too expensive relative to their risk hedging benefits (note that buying 50,000 swaps at the indicated swap price has an expected cost of \$220,000). Of course, if a more attractive swap price were available, then such swaps could play a role in an efficient hedging strategy - here they clearly do not.

\subsection{Simultaneous Hedging across Multiple Products}

Simultaneous hedging across multiple commodities is, of course, desirable to account for natural diversification, even if the commodities are uncorrelated (thus, staying within a given spend target is less expensive in terms of hedging costs if one considers the entire portfolio of commodities and hedge instruments rather than separate hedging for each commodity). This is especially true if the commodities are correlated among themselves or with a common additional commodity. For example, crude oil options or swaps might not be efficient when considered only as a hedge against HDPE price volatility, but they could very well be efficient when considered against the joint portfolio of PP, PET and HDPE (since all three are clearly correlated with crude oil, the basic feedstock for their manufacture). The very simple illustrative results of this case could be extended to a portfolio of instruments, including swaps, naphtha positions, etc. and across multiple commodities. It should be noted, however, that each commodity has its own special characteristics and typically requires a team of competent supply managers to understand and track movements of that commodity. Higher level portfolio strategies across multiple commodities require careful coordination across the individual commodity buying teams.

\section{IMPLEMENTATION CHALLENGES}

Figure 6 reflects the necessity to deploy an organizational infrastructure for effective deployment of risk management strategies within the Supply Management organization. The key to success in the market is responsiveness, which is defined as the time between getting critical market information, analysis, synthesis, and decision taking with respect to the current and desired position in the market, through implementation (e.g., a buy or cover order placed).

\section{CONCLUSIONS}

Companies with a strong tradition of internal financial control and accountability tend to view the use of financial tools for supply management in the following light: Competitive buying decisions require the use of financial tools for optimal performance. The use of financial tools, however, needs to be strongly regulated to manage the risk and comply with accounting rules. In particular, maximum limits on real money exposures for hedging have to be clearly measured and controlled. There is a clear recommendation from research on risk management in general in terms of 'learn to walk before you run', promoting 'virtual' hedging pilots before implementing these and putting real money at risk. Simulation plays a crucial role in this process. 


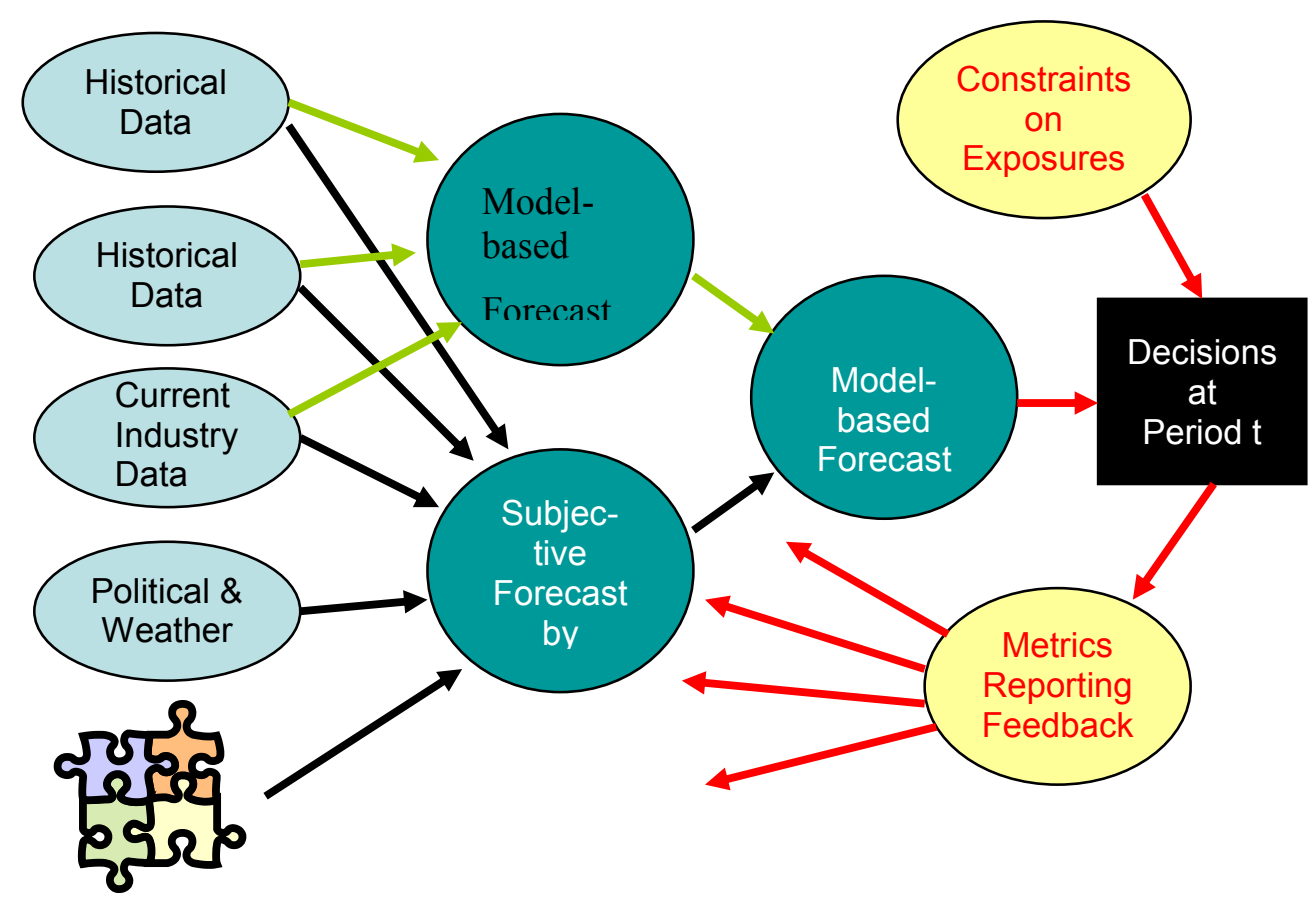

Figure 6: Data-decision-feedback cycle.

\section{ACKNOWLEDGMENTS}

The authors wish to thank Dr. Uwe Schulte, VP Global Procurement at Unilever, for his support.

\section{REFERENCES}

Crouhy, M., R. Mark, and D. Galai. 2000. Risk Management. McGraw-Hill Trade.

Hong, L. J., and B. L. Nelson. 2009, December. "A Brief Introduction to Optimization via Simulation". In Proceedings of the 2009 Winter Simulation Conference, edited by M. D. Rossetti, R. R. Hill, B. Johansson, A. Dunkin, and R. G. Ingalls, 75-85. Piscataway, New Jersey: Institute of Electrical and Electronics Engineers, Inc.

\section{AUTHOR BIOGRAPHIES}

PAUL KLEINDORFER was the Paul Dubrule Professor of Sustainable Development and Distinguished Research Professor at INSEAD and the Anheuser Busch Professor of Management Science at the Wharton School of the University of Pennsylvania. Dr. Kleindorfer's research focused on risk management and sustainable operations. He graduated with distinction from U.S. Naval Academy and earned a doctorate from Carnegie Mellon University.

ENVER YÜCESAN is a Professor of Operations Management at INSEAD in Fontainebleau, France. His research interests focus on simulation optimization and its application to supply chain management. He has served as Proceedings co-editor for WSC'02 and as Program Chair for WSC'10. He is currently a member of the WSC Board of Directors, as a representative of INFORMS I-SIM. He holds a PhD in Operations Research from Cornell University and is a die-hard Boilermaker. His email address is enver.yucesan@insead.edu. 